Numerical Calculation of Surface Waves:

A Modified ZUNI Code with

Surface Particles and Partial Cells 
This report was prepared as an account of work sponsored by the United States Government. Neither the United States nor the United States Atomic Energy Commission, nor any of their employees, nor any of their contractors, subcontractors, or their employees, makes any warranty, express or implied, or assumes any legal liability or responsibility for the accuracy, completeness or usefulness of any information, apparatus, product or process disclosed, or represents that its use would not infringe privately owned rights.

Printed in the United States of America. Available from

National Technical Information Service

U. S. Department of Commerce

5285 Port Royal Road

Springfield, Virginia 22151

Price: Printed Copy $\$ 900$; Microfiche $\$ 0.95$

${ }_{4}, 00$ 


\section{Numerical Calculation of Surface Waves: \\ A Modified ZUNI Code with Surface Particles and Partial Cells}

by

Anthony A. Amsden

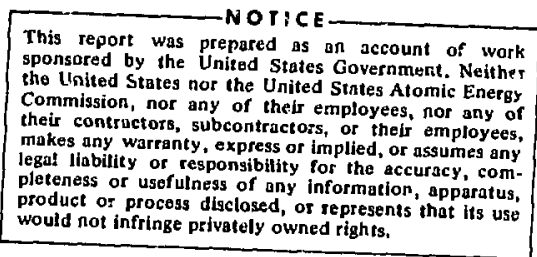




\section{CONTENTS}

ABSTRACT

I. INTRODUCTION

II. ZUNI CODE MODIFICATIONS

A. Surface-Marker Particles

1. Adding the Surface-Marker Capability

2. Using Surface Markers as the Only Particles 4

B. The Partial-Cell Treatmen.

1. The Fully Submerged PAR Cell

2. The Fartial-Surface Cell 6

III. CaLCULATIONAI EXAMPLES

ACKNOWLEDGMENTS 18

REF ERENCES $\quad 18$ 
NUMERICAL CALCULATION OF SURFACE WAVES:

A MODIFIED ZUNI CODE WITH SURFACE PARTICLES AND PARTIAL CELLS

by

Anthony A. Amsden

ABSTRACT

\begin{abstract}
Extensions to the or 1ginal Simplified Marker-and-Cell (SMAC) method computing program, ZUNI, are described. These Include Nichols and Hirt's Improved free-surface treatment and, In addition, a partial-cell treatment that allows an obstacle face to pass through cell diagonals. Applications of the midifled program are shown by calculations of wave runup on both submerged and exposed sloping beaches. The validity of the approach for studies of actual tsunam 1 waves has been demonstrated.
\end{abstract}

\section{INTRODUCTION}

The Marker-and-C 11 (MAC) method ${ }^{1}$ was the first successful numerical technique for calculation of viscous, incompressible flows with a free surface. After 1ts introduction, much attention was given to devising sore accurate treatments of the freesurface boundary conditions, which orlginally used only simple approximations. Hirt and Shannon ${ }^{2}$ incorporated Improved approximations to the normal stress conditions, and showed the necessity for satlsfying the sangential stress condtione as well. The Improved stress conditions were included in the zUNI code, ${ }^{j}$ which was the original simplifiedMarker-and-Cel1 (SMAC) wethod computing program. In the orlginal MAC and SMAC verstons, all pressures or pseudopressures were spectfied at cell centers. Chan et al. 4 developed a technlque for more accurate delineation of the free surface. This permitted the pressure equation to be adfusted so that the freeBurface pressure could be specified at the surface 1tself, rather than at the center of the surface cell. Nichols and Hirt ${ }^{5}$ modifled the Chan procedure, and devised a technique for defining the fluid surface by a set of ourface-marker particles that move with the local flutd velocicy. These particles allow surface-cell pressures in MAC to be accurately specified by means of linear interpolation (or extrapolation) between the known valtes of pressure In the nearest full cell and the desired fluld surface pressure. In addition to providing l'mproved treatment of cell variables at the surface, Nichols and Hirt have clarffled the use of the varlous possible free-surface stress conditions.

This report deacribes a modified version of the or iginal zUNI code which includes the Nichols and Hirt free-surface Improvements. A partal-cell tregtment that allows a rigid free-silp obstacle to be placed through cell diagonale has also been Included. The desired boundary slope is obtained by choosing the approprlate aspect ratio for the cells of the resh.

Valldity of the free-surface techniques had prevlously been demonstrated by the accurate, smooth, and stable calculation of large-amplitude surface motions, but the main obfective in this modified version of zUNI is to incorporate the highly accurate treatment now avallable for low-amplitude free-surface motions, In particular, to follow the growth of waves as they interact with a beach or continental slope. The success of the project has been demonetrated by the numerical simulation of tounami waves with much greater accuracy than was posstble previously. 6 Since such waves may have width-to-height ratios on che order of $10^{5}$ to 1 , 
for whlch the surface would appear to be entirely flat, the free-surface treatment must respond to the very slight varlations that extst in the vertical direction.

Section II of this report describes the modiflcations to ZUNI to Include, first, the surfacemarker particles and then the parilal-cell treatment. Section III 111ustrates the capabilities of the modifled ZUNI code by means of a number of representative calculations. Some discugsion of graphics for displaying calculational results is presented, espectally concerning techniques for visualizing the extreme low-amplitude, long-wavelength flows. Detalled discussion of the numerical results and comparison with experimental data are provided by Mader. 6 In the rest of this report, fanillarity with the basic SMAC technique ${ }^{3}$ is assumed.

\section{ZUNI CODE MODIFICATIONS}

A. Surface-Marker Particles

1. Addizg the Surface-Marker Capab11tty. The

N1chols and Hirt scheme uses a set of special marker particles spaced at intervals along the surface, the exact surface configuration being given by line segments foining the particles in gequential order. These surface markers are moved with the local fluld velocity, just as ordinary marker particles are. The value of some fleld variable at the center of a surface (SUR) cell is based upon a Iinear interpolation or extrapolation using the known values at the free gurface and the nearest full (FuL) cell center. The interpolated value is a function of the distance from the actual surface to the center of the nearest FUL cell, along a line connecting the centers of the SUR and FUL cells. Th1s distance is denoted by d In Fig. 1. The general form of the Interpolation is

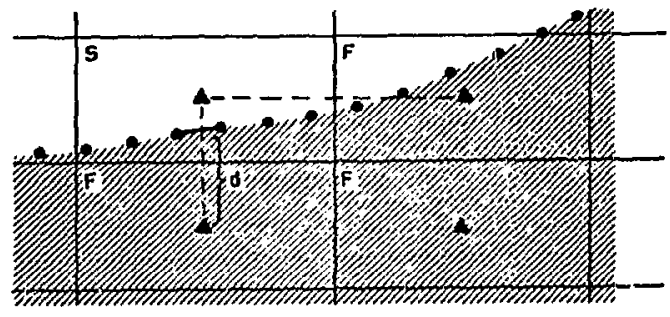

F1g. 1. The Interpolation neighbor of the SUn cell Is the ful cell below $1 t$.

$$
q_{\text {SUR }}=(1-n) q_{F U L}+n q_{\text {free surface }} \text {, }
$$

where $q$ is some cell-centered vartable and $n$ is the ratio of the distance between cell centers to the distance d. When the SUR cell has more than one FUL neighbor, as in Fig. 1, the interpolation process chooses the neighbor whose intersection point

lies nearest the center of the SUR cell.

Once every cycle, values of $n$ are calculated and stored for every SUR cell in the wesh. In add1tion, a special flag, NF, that Indicates which of the four neighboring cells is the irterpolation nelghbor, is stored for every SUR cell. NF is 1,2, 3 , or 4 for a ntarest FUL neighbor on the right, top, left, or bottum, respectively. NF a 5 is used to Indicate the SUR cell has no FUL nelghbor, a case that requires spectal treatment. Cell-storage arrays must be created for $n$ and $N F$, and a separate particle-storage array must be created for the surface-marker coordinates.

When the ourface-marker-particle feature is Incorporated in SMAC, the code must be modified and expanded in a number of pleces. Particular attention must be given to the following ten polints: (1) A single, new, Input variable specifying the approximate surface-marker spacing controls the use of the surface-marker feature. We use a quantxty DSP ( $\delta$ spacing), defined as the rectprocal of the desired average number of surface particles across a cell. In the examples in Sec. III, DSP $=0.31 s$ a typtcal value; it will matntatn approximately 10 particles for every $3 \delta x$ of surface. By specifying DSP $=0$ in the Input, we omit the surface-marker option from a calculation. When DSP > 0 , the setup must generate a set of surface markers ordered from left to right along the free surface, with the end particles just slightly outBide the mesh to "tie" the set Into the boundarles. Fallure to do this will allow the particle line to recede from the walls.

(2) In the Reflagging section, the surface markers must be allowed to particlpate fust as fully as the regular markere.

(3) Once every cycle, the set of ourface markers must be edited. First, delete any surface markers In FUL cells. Second, remove surface particles 
frum coalescing regions whenever they become too closely spaced to be effictent. The minimum spacing we allow in cell units is DSP/2. Third, allow for the opposite situation in expanding regtons; we create additional particles whenever the spacing exceeds 1.1 times DSP, regardliss of the iype of cell in which the new particle is p.laced. Finally, the Reflagging (step (2) above) is repeated with this revised surface-marker configuration.

(4) Following completion of step (3), a sweep is made through the mesh, calculating new values of $n$ and NF for every SUR cell encountered.

(5) In the $\theta$ calculation, set

$$
\begin{aligned}
& \theta_{\text {SUR }}=\left(\theta_{\text {SUR }}-\theta_{\text {FUL }}\right) \eta+\theta_{\text {FUL }} . \\
& \left(\text { If NF }=5, \theta_{\text {SUR }}=0 .\right)
\end{aligned}
$$

(6) It is crucial that the FUI-cell interpolation neighbors be underrelaxed to prevent an oscillating instability in the $\psi$ fleld from arising in the 1teration. The reason for this is described by Nichois and Hirt. 5 We define a relaxation parameter $\alpha_{\text {FUL }}$ as a function of $\eta$ and the Input $\alpha$, now called $\alpha_{0}:$

$$
\alpha_{F U L}=\min \left\{\alpha_{0}, \alpha_{F U L},\left[\frac{4\left(1+\alpha_{0}\right)}{4-\left(1+\alpha_{0}\right)(1-n)}-1\right]\right\}
$$

Thls selection process calses $\alpha_{\text {fuL }}$ to respond to the most stringent case when the FUL cell is serving as the Interpolation neighbor of more than one SUR cell oimultaneously. The simplest way to handle the varying $\alpha_{\text {FUL }}$ values, which must be adjusted every cycle, is to create a cell-storage array for $\alpha_{1}^{j}$ values, Initlalizing $\alpha_{1}^{j}=\alpha_{0}$ for all cells, and then selectively resetting $\alpha_{i}^{j}$ in all FUL cells.

(7) In the fteration procedure, after every oweep of the FUL cello, perform a second sweep, setting $\psi_{\text {SUR }}=(1-\eta) \psi_{\text {FUL, assuming that } \psi \text { at the free sur- }}$ face 1s zero. This loop is inserted at the place where exterint $\psi$ values are set. When NF $=5$, set $\psi_{\text {SUR }}=0$.

(8) The surface-marker particles are woved and plotsed In nearly the oame manner as the regular marker particles. When plotting the surface markerb, we represent them by an aster $18 k$ rather than the usual dot, to provide a defintte viaual distinction between the two types of particles.
(9) The condition of vantshing tangential stress,

$$
\frac{\partial v}{\partial x}+\frac{\partial u}{\partial y}=0
$$

18 satisfied in 2UNI in setting the tangential velocities fust outside the free surface, However, this modifled version of the code is intended primarily for high-Reynolds-number bore and wave stud1es, for which 1 is is not posstble to resolve boundary layers, as they are much thinner than a cell dimensiol:. Accordingly, we have found that a "freeslip" condition ( $u_{\text {out }}=u_{1 n}$ ) gives a much better approximation to the physical velocity profile. 5 In ZUNI, this change simply involves the deletion of the $\delta r / \delta z$ and $\delta z / \delta$ r terms from the four equations used In setting the just-outside tangential veloc1t les in statement No. 330.

(10) Several possible cases must be considered in setting normal velocities on empty (EMP) cell faces of SUR celis for bore and wave calculations, the treatment depending upon the number and location of the RPP nelghbors:

(a) If the SUR cell has one empty face, the velocity on that face should be chosen auch that $\nabla \cdot \vec{u}$ - 0 for the cell, which is the usual treatment.

(b) If the suR cell has elther three empty faces or two empty faces opposite one another, no general prescription can be stated and the standard ZUNI treatment is recormended.

(c) If the SUR cell has two adjacent empty faces, however, the atandard 2UnI treatment is iaapproprlate. Conslder a wave front propagating $f_{r o m}$ left to right. As indisated in F1g. 2, the origina: treatment sets the u-velocity component across

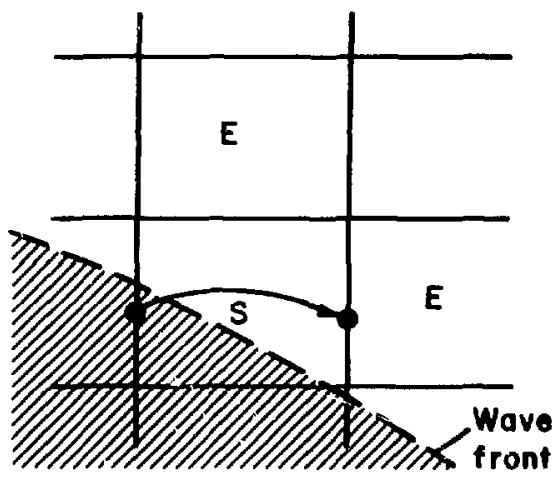

E18. 2. Or 1ginal 2UNI velocity treatment for sUR cell with EIP neighbors on right and above. 
laterally. For bore and wave applications, however, this allows momentum to be transferred forward too rapidly, causing a noticeable "skiming" of the surface. The wave front must be retarded somewhat to compare favorably with experimental deta for flows of this type. This can be accomplished by setting $u=u_{F U L}$ from the nearest FUL neighbor. In general, this will be the cell below, which should also be the interpolation nelghbor. Finally, $v_{\text {TOP }}$ is chosen to ensure that $\nabla \cdot \vec{u}=0$ for the SUR cell. Fig. 3 shows the recommended treatment for the configuration of Fig. 2 .

In ZUNI, this change in setting velocities of SUR cells with adjacent empty faces is made in two places for the geometries we are considering: SUR cell with EMP faces on right and above:

$$
u_{1+\frac{1}{2}}^{j}=u_{1+\frac{1}{2}}^{j-1}
$$

SUR cell with EMP faces on left and above:

$$
u_{1-\frac{1}{2}}^{j}=u_{1-\frac{1}{2}}^{j-1} \text {. }
$$

These changes occur at statement No. 653, which becomes "U(I,J) $=\mathrm{U}(I, J-1)$," and at statement No. 655 , which becomes "U(I-1,J) = U(I-1,J-1)."

\section{Using Surface Markers as the Only Particles.}

With the free-gurface marker-particle treatment added to the SMAC code as described abnve, the regular marker particles generally cease to be useful, and it is practical to modify the code to run without them. This will not only enhance computing efficlency, but will also allow greater freedom in spectfying conditions at the inflow boundary.

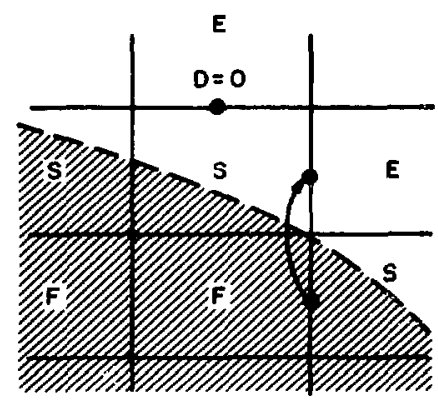

F1B. 3. Modifled ZUNI treatment appropriate for bores and waves.
Consider that a true physical wave oscillates, and to model this oscillation requires the specification of negative as well as positive fluid velocities at an "Inflow" boundary. This, in turn, would require special treatment for any regular marker particles at this bounciary, as they would attempt to leave the system and subsequently reenter.

In the ZUNI code, changes need to be made at only four places to delete the use of regular marker particles:

(1) Turn off regular marker-particle generation with a "GD $\mathrm{T} \emptyset 90$ " Insirted fust before statement No. 50. Note that the "NX, NY, ---" etc, data card remalns in use, however, to define the region to be surrounded by surface-itarker particles.

(2) Insert a "Pre-flagger" Just after statement No. 262. This routine consists of a reversed double $D$ loop that sweeps the grid from top to bottom. The logic is to flag all cells as EMP in each column of cells until a cell that contains surface markers is reached. This cell is flagged SUR, belor which all remaining cells in the column are flagged FUL. Be carefu1, however, not to destroy any DB (obstacle) flags. The Pre-flagger prevents the subsequent, ordinary Reflagger from reflagging the FUL cells to EMP, which 1t would otherwise do because they contaln no particles.

(3) The UL (Inflow-boundary velocity) can now be a pertodic function, allowing the flow to truly oscillate. The ordinary limitation of a minimum inflow velocity of zero (given by $\sin ^{2} \omega t$, for example) is removed.

(4) The creation of columns of regular marker particles at the inflow boundary to bypassed by rewriting statement No. 735 as "NP = NPN $\$ G \emptyset T \emptyset 770 . "$ (Former1y, the "G $\mathrm{T} \emptyset 770$ " was done only $1 \mathrm{~T}$ TYPE $=0$, which meant that the problem contained no inflow boundary.)

\section{B. The Partial-Ce11 Treatment}

For simplicity, we restrict discussion of the partial (PAR) cell boundary condtition to allow only a rigid, free-slip boundary that follows cell diagonals. The boundary slope is adjusted by selecting the approprlate aspect ratio of the cells, $\delta y / \delta x$, as shown In Fig. 4. Furthermore, the lower-right half of the cell is the obstacle side, and the upper-left half is the fluid side. A sloping boundary in this particular orfentation is convenient for 


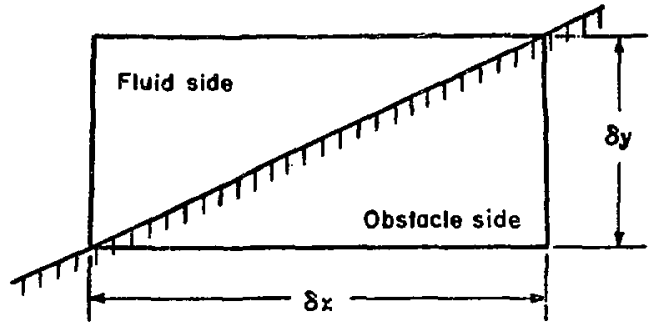

F1g. 4. The partial (RAR) cell as described here.

use with the Inflow boundary along the left side of the mesh in ZUNI. From the expressions described below for this case, one can derive similar exp̃resslons for the other three possible orlentations of this diagonal boundary.

In 2UNI, we set TYPE = 2 in the Input data to distinguish the partial-cell obstacle setup from the original rectangular (TYPE = I) obstacle. We then use $L 5$ and $L 6$ as the two a1menstons required to specify the location and extent of the sloping wall, as Indicated in Fig. 5. These dimensions are given In Integer numbers of cells, and we Ifmlt $\bar{I}>L 5>1$ and $\overline{\mathrm{I}}>\mathrm{L6}>\mathrm{L} 5$. The cells that 11e below the PAR cell In each column are $D B$ (obstacle) cells, as are the cells in the level portion of the obstacle to the right of 16 . The PAR cells are given a flag $[F(I, J)]$ of 0.5 in ZUNI, regardless of whether the fluid side of the cell is submerged or exposed. Th1s fils in as well as posaible with the original flagging schene, allowing most of the flag tests on ",GE." and ".LE." to remaIn unchanged.

It is conventent to describe the fully subw merged and the partially exposed or "partial-surface" cells separately. First, consider the simpler case:

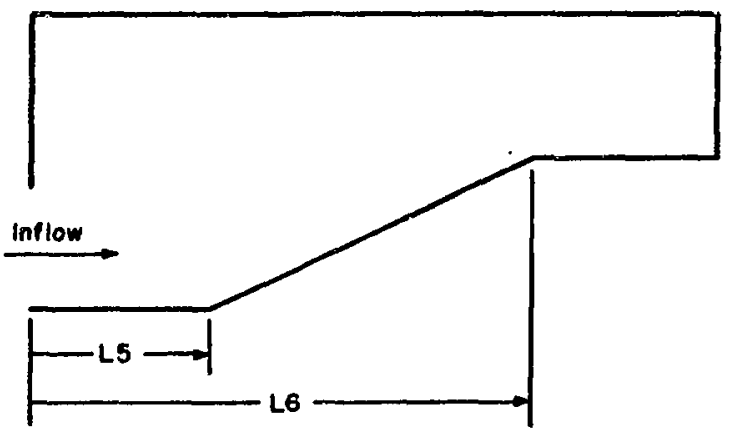

F18. 5. The diggonal boundary in ZUNI, created from the partial cells of FIg. 4.
1. The Fully Submerged PAR Cell.

(a) Zeroes are permanently stored In the appropriate PAR-cell velocity locations (F1g, 6), Just as In the $\$ B$ cells.

(b) $6=0$ in the PAR cells.

(c) The $\tilde{\mathrm{u}}$ and $\tilde{\mathrm{v}}$ equations must be modified to a1low for the presence of the (free-slip) diagonal boundary. In calculating $\tilde{u}_{1+b_{2}}^{j}$, sense whether cell $\left(\begin{array}{l}j \\ 1+1\end{array}\right)$ is a $P A R$ cell. If it 1 , the i equation to be used 1s:

$$
\begin{aligned}
\frac{\tilde{u}_{1+\frac{1}{2}}^{j}-u_{1+\frac{1}{2}}^{j}}{\delta t} & =\frac{u_{1+\frac{1}{2}}^{j} u_{1-\frac{1}{2}}^{j}-\left(u_{1+\frac{1}{2}}^{j}\right)^{2}}{\delta x} \\
& +\frac{u_{1+\frac{1}{2}}^{j} v_{1}^{j-\frac{1}{2}}-(u v)_{1+\frac{1}{2}}^{j+\frac{1}{2}}}{\delta y}+\frac{\theta_{1}^{j}-\theta_{1+1}^{j}}{\delta x} \\
& +g_{x}+v\left[\frac{u_{1+\frac{1}{2}}^{j+1}-u_{1+\frac{1}{2}}^{j}}{\delta y^{2}}-\frac{v_{1+1}^{j+\frac{1}{2}}-v_{1}^{j+d_{2}}}{\delta x^{\prime} \delta}\right] .
\end{aligned}
$$

If cell $\left(\begin{array}{l}j \\ 1\end{array}\right)$ is itself a PAR cell, its $\tilde{v}$ (at ${ }_{1}^{j+l / 2}$ ) is givea by:

$$
\begin{aligned}
& \frac{\tilde{v}_{1}^{j+l_{1}}-v_{1}^{j+l_{1}}}{\delta t}=\frac{\left(v_{1}^{j+\frac{1}{2}}\right)^{2}-v_{1}^{j+\frac{1}{2} v_{1}^{j+3 / 2}}}{\delta y} \\
& +\frac{(u v)_{1-d_{2}}^{j+l_{1}}-u_{1+l_{2}}^{j+1} v_{1}^{j+d_{1}}}{\delta x}+\frac{\theta_{1}^{j}-\theta_{1}^{j+1}}{\delta y} \\
& +g_{y}+v\left[\frac{u_{1-\frac{1}{y}}^{j+1}-u_{1-\frac{1}{2}}^{j}}{\delta x \delta y}-\frac{v_{1}^{j+\frac{1}{2}}-v_{1-1}^{j+\frac{1}{2}}}{\delta x^{2}}\right] \text {. }
\end{aligned}
$$

(Although a freeslip dlagonal boundary is appropriate for the modifled program described here, the velocity equations could be adfusted stralghtforwardly to account for the presence of a noslip boundary instead.)

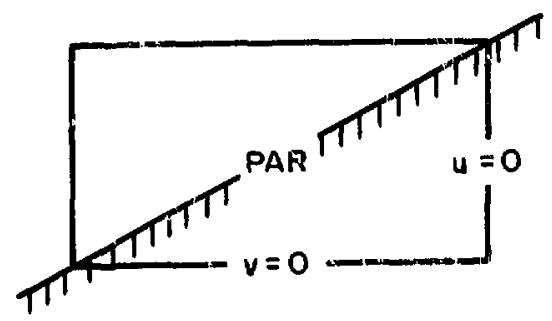

F1g. 6. The two velocities that are pexmanently zeroed In any PAR cell. 
(d) The $\tilde{D}$ for the partial cell to given by:

$$
\tilde{D}_{1}^{J}=\frac{\tilde{v}_{1}^{J+y_{2}}}{\delta y}-\frac{\tilde{u}_{1-x_{2}}^{J}}{\delta x} \text {. }
$$

With the appropriate velocities zeroed, as in item (a), the regular D̃ formula will automatically give this result.

(e) In the 1teration, submerged PAR cells, In addition to the FUL cells, particlpate in the relaxation process. The $\psi$ of such a PAR cell $\left(\begin{array}{l}1 \\ 1\end{array}\right)$ is given by:

$$
\begin{aligned}
{ }^{h+1} \psi_{1}^{j} & =\frac{1+\alpha_{1}^{j}}{\left(\frac{1}{\delta x^{2}}+\frac{1}{\delta y^{2}}\right)}\left(-\tilde{D}_{1}^{j}+\frac{h^{h+1} \psi_{1-1}^{j}}{\delta x^{2}}+\frac{h_{\psi_{1}^{j+1}}^{j+1}}{\delta y^{2}}\right) \\
& -\left(\alpha_{1}^{j}\right)\left(h_{1}^{j}\right) .
\end{aligned}
$$

(f) is the particle movemenc, the zero velocities stored on the bottom and right faces of PAR cells In 1 tem (a) must be effectively tgnored. Fallure to do so will cause a false drag along a wall that 1s meant to be truly free slip. The weighting scheme should use the calculated $u$ and $v$ velocity components from the fluld side for the other one or three velocitles, as required. The locartion of a velocity component is tested to see whether or not 1t $11 e s$ on the fluld olde of the obstacle, and the calculared $u$ or $v$ is used if it does not, for the components indicated in Fig. 7.

Next, consider the extensions of the bastc treatment to allow for the wore complex case.

\section{The Partla1-Surface Cell}

(a) The line of surface-marker particles must cut aff at the diagonal interface. As in the basic burface-marker usage described in Sec. $A$, the final
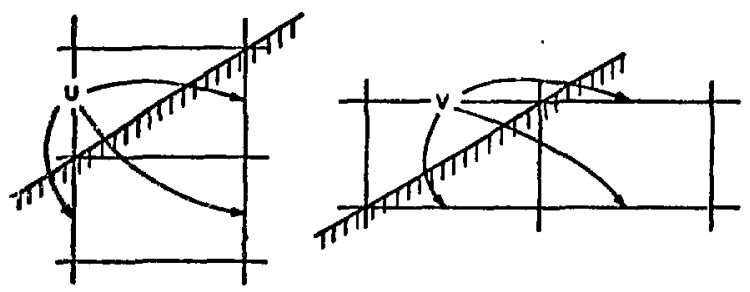

F1g. 7. Veloc1ty-welghting adjustment for part1cles near the free-slip diagonal boundary. marker must be constrained to remain fust inside the obstacle to "t1e" the particle line in, whereas all other surface markers must be kept on the fludd outside the obstacle, as shown In F1g. 8. Furthermore, it is cruclal that the firs 1 marker be kept fron moving too deeply into the obstacle, or it will eventually move to an area of zero velocities and become frozen. If regular marker particles are in use, and one moves into the obstacle, It should simply be deleted from the system. More specifically, zUNI has the following special particle treatments:

If a regular marker particle moves into the obstacle, it is deleted from the system.

If a surface marker (not the final one) moves into the obstacle, nothing is done at particlemovement tfme, but the particle is deleted later in the added region where spacing is checked and surface markers are normally deleted or created.

If the final surface marker moves out of the obstacle and into the fluld region, 1ts $x$ or $y$ coordinate is adjusted to place it back in the obstacle.

If the final surface marker moves too deep inside the obstacle (we consider any distance greater than 0.1 cell, In untt-cell dimensions, as too deep), the nearest surface-marker particle lylng outside the obstacle is located, and a line is drawn connecting these two particles (FIg. 9). The final surface marker is moved along this line to a posttion 0.05 cell inside the obstacle. The constraint of the final surface marker to lie within this $0.05-$ cell belt applies equally alui; the level face of the obstacle.

(b) $\theta=0$ in partlal-surface cells, just as in submerged partial cells.

(c) Veloc1t1es must be opectally set near partlalsurface cells. Since the double $D$ loops advance from left to right and then upward through the mesh, havling the diagonal boundary on the lower right

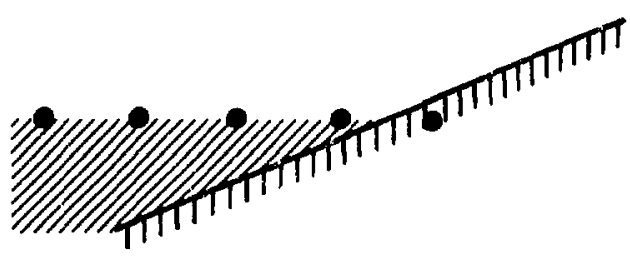

F18. 8. The final surface-marker particle should 11e In the obstacle. 


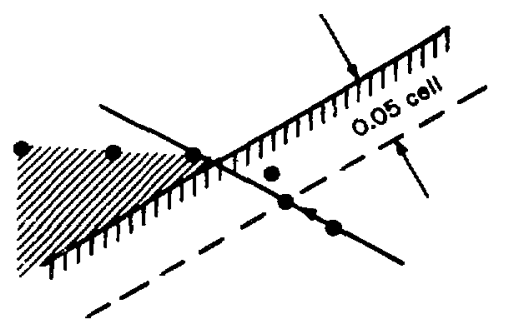

F1g. 9. The final particle is moved back up closer to the surface of the obstacle whenever it moves in soo deep.

silows special velocity adfustments to be easily propagated upward along the diagonal near the intersection of surface and boundary. Velocities are set in the order indicated for the three cases shown in Fig. 10.

(d) For the $\psi$ iteration, there are a number of important conelderations,

(1) For the PAR cells, the following cases are posstble.

(a) NF = 0 in the PAR cell, meaning that 1t has no interpolation neighbor. Th1s will happen if:

- The PAR cell 1s fully submerged (the cell to itg left is FUL), and the surface particle line does not intersect the line connecting cell centers, as shown in Fig.

11. The treatment here is to Include the PAR cell in the iteration, as mentioned In 1 (e) above.

- The cell to the left of the PAR cejll is SUR or EMP, as in Fig. 12. In elther case, the PAR cell is excluded from the iteration. If the neighbor on the left is EMP, the PAR cell lies entirely above

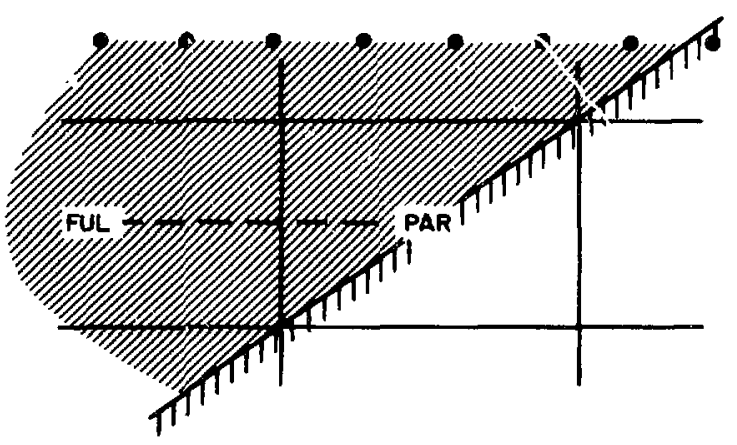

Fig. 11. The PAR cell is included in the $\psi$ iteration.

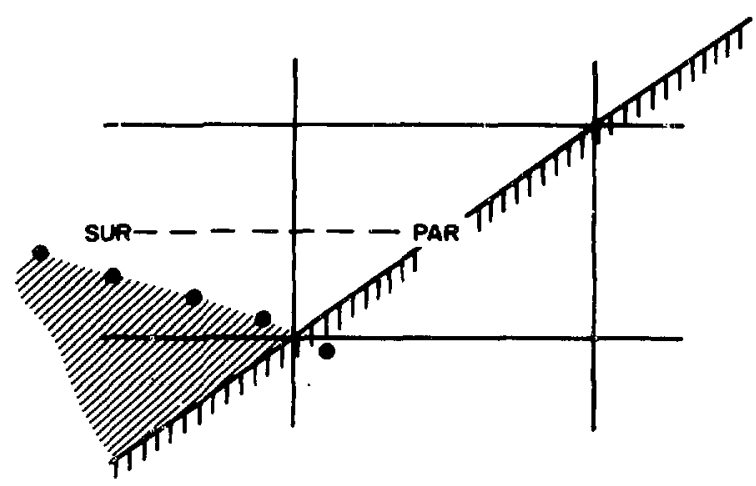

F1g. 12. The PAR cell is excluded from the $\psi$ iteration if the cell to the left 18 EMP or SUR.

the surface, and $\psi$ for the PAR cell is not needed. If the cell to the left is a SUR cell, however, set $\psi_{P A R}=\psi_{\text {SUR }}$ * (b) NF $>0$ in the PAR cell if the line of surface-marker particles pesses through the PAR cell, and a (FUL) interpolation neighbor can be found on the left (F1g, 13).
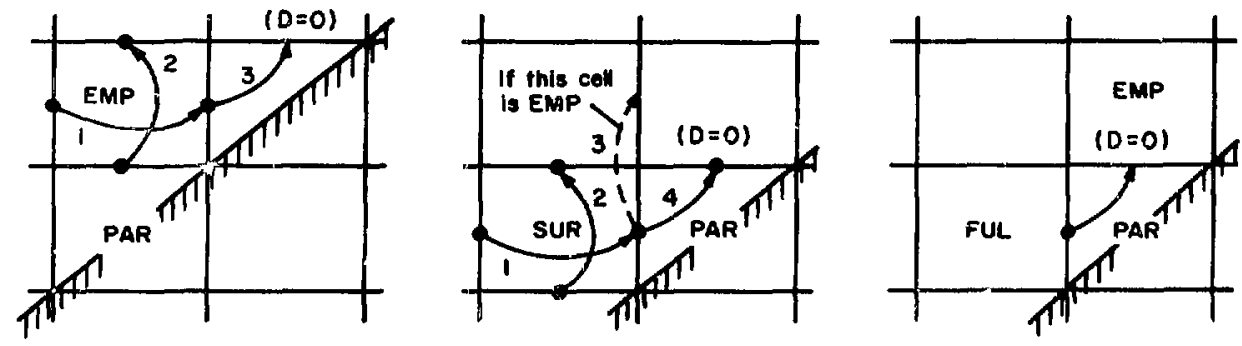

Fig. 10. Propagation of velocttieg near the surface. 


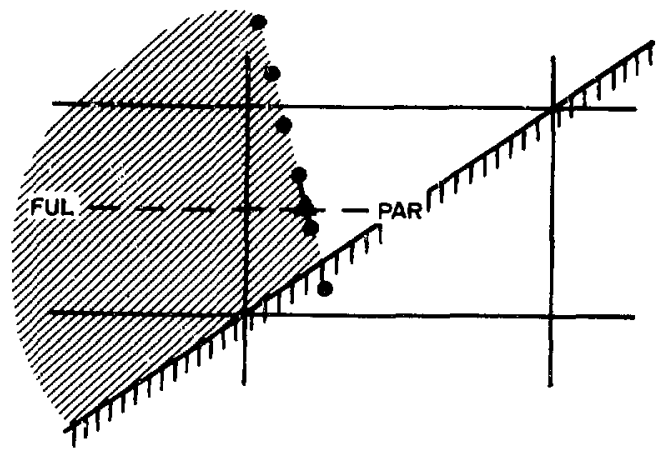

Fig. 13. The $\psi$ in the PAR cell is interpolated from the FUL-cell neighbor.

The treatment of this partial-surface cell Is the same as that of a regular SUR cell; the intersection point of the particle line with the line connecting cell centers provides the $\eta_{\text {PAR }}$ value. The PAR cell is not iterated; instead,

$\psi_{\mathrm{PAR}}=\left(1-\eta_{\mathrm{PAR}}\right) \psi_{\mathrm{FUL}}$, which is the same formula as that used for $\Psi_{S U R}$.

(2) For the SUR cells with PAR cells below, several cases must be considered. The basic principle is that PAR cells can serve as interpolation neighbors for SUR cells, and that they have the same power as a FUL cell in this respect.

(a) If the PAR celi is fully submerged and $n_{\text {SUR }}<2$, as 1n Fig. 14, then the PAR cell can serve as the interpolation neighbor for the SUR cell. The PAR cell, which

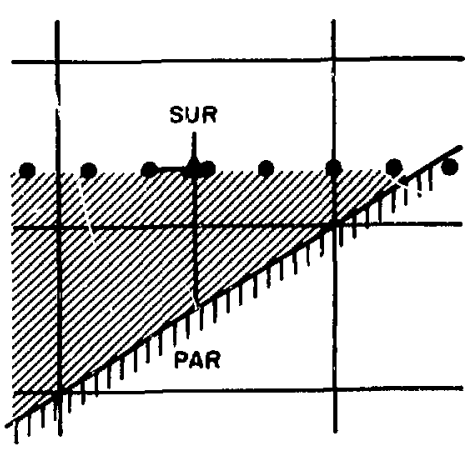

Fig. 14. The PAR cell is the interpolation nelghbor for the SUR cell. participates in the Iteration, must be underrelaxed in the same manner as a FULcell Interpolation neighbor. Set $\psi_{\text {SUR }}=(1-n) \psi_{\text {PAR }}$.

(b) If, however, the point of intersection of the line of surface markers and the line foining cell centers lies within the PAR cell, as in Fig. 15, then the partial cell is not considered to be fully submerged. In this case, $\eta_{S U R}>2$, and $1 t$ is crucial that this $\eta$ not be used in setIng $\psi_{S U R}$, as the $\psi$ iteration would diverge even with underrelaxation of $\psi_{\mathrm{PAR}^{*}}$. When a SUR cell has a PAR cell below as an interpolation neighbor and $n>2$, set $n$ to $2 / 3$. (c) The third possiblitty is that the particle line does not intersect the line folning cell centers, as in Fig. 16. Unless the cell to the left of the SUR cell is a FU: cell, the SUR cell has no interpolation neighbor, and $\psi_{\text {SUR }}=0$.

\section{CALCULATIONAL EXAMPLES}

In this section are examples from several calculations made with a modified version of the zUNI code which includes the sloping bottom boundary and improved free-surface treatment. This code version has shown that it is, indeed, possible to make numerical studies of tsunami vaves. These waves had previously proved impractical to calculate because of the severe resolution problems that arise when dealing with waves of such an extreme wavelengthto-amplitude ratio, although successful caiculations

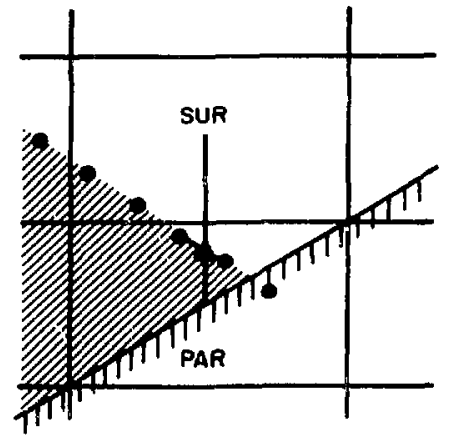

F1g. 15. The PAR cell can still serve as the 1nterpolation neighbor for the SUR cell, but $\eta$ must be reduced. 


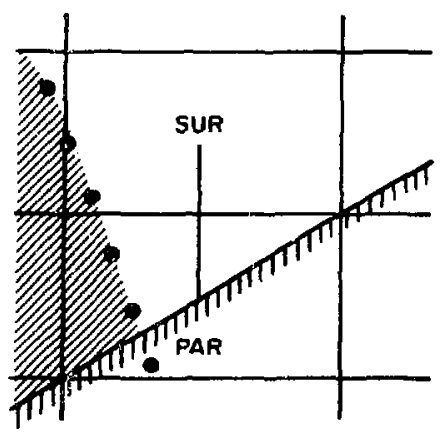

Fig. 16. The PAR cell cannot serve as an interpolation neighbor for the SUR cell. Unless the cell to the left of the SUR cell is FUL, $\psi_{\text {SUR }}=0$. See also F1g. 13 .

of waves of milder proportions have been reported. ${ }^{7}$

Tsunami waves are generally of little concern when they are travelling over deep water, but when such a wave approaches an Island or a continent, the decreasing ocean depth causes the speed of the wave front to decrease and the amplitude to increase drastically. Many disasters have resulted from shoaling waves, and there has, accordingly, been much interest in understanding the interaction of tsunami-type waves with continental shelves and beaches in order to devise more effective means of combating their destructive effects.

The princlple of decreasing wrvelength with a corresponding increase in amplitude is 1llustrated In the Idealized example of $\mathrm{FIg} .17$, in which the wave proportions are exaggerated for clarity. The figure shows a sequence of particle plots from the calculation of a single solitary wave passing down a channel and reflecting of a rigld vertical wall at the right boundary. The incoming wave passes over a submerged sloping boundary, and the resultIng decrease in charael depth produces the above described change in ratio of wavelength to amplitude. The free-surface-marker particles are represented by heavy asterisks to distinguish them from the regular marker particles. The aspect ratio of the computing cells is $2: 1$, giving a alope of $26^{\circ}$ $34^{\prime}$ on the diagonal boundary.

The first frame in Fig. 17 shows the 1nitial particle configuration before the wave has been introduced, and the succeeding frames show the progress of the wave and 1 ts reflection. The eleven frames in Fig. 18 are velocity vector plots for this problem, with times that correspond to those of the final eleven frames of Fig. 17.

The more realistic calculation of a tsunami wave requires a much longer mesh with a more gradual slope. A typical mesh for this purpose is shown In Fig. 19, which is drawn far from true proportion to make its dimensions readable. Note that the aspect ritio of the cells is $25: 1$; the resulting slope of the diagonal boundary is $3^{\circ} 50^{\prime}$. For a detalled study of the surface configuration, a numerical listing of the coordinates of the surface-marker particles is important, but it is also extremely useful to visualize the wave dymamics graphically. A standard particle plot of this grid in 1tg true proportion is useless in 1llustrating the wave. As shown In FIg. 20, the grid appears practically as a 1ine. Even with the vertical scale exaggerated as much as the f1lm frame w1ll allow, the free surface st111 appears flat throughout the entire calculation (F1g. 21), because the amplitude variation of the wave occurs over a very small fraction of a cell he1ght.

An effective visual plot must, therefore, not only exaggerate the vertical scale, but must also eliminate 1ts lower part. This was done for the sequence of xiy plots of the free-surface-marker particles In Fig. 22. The plotting region is square, but whereas the horizontal scale covers $459,000 \mathrm{~m}$ of ocean surface, the vertical scale covers only $3.5 \mathrm{~m}$ near the surface (from $4549.5 \mathrm{~m}$ up to $4553 \mathrm{~m}$ ) and the ocean floor (at $0 \mathrm{~m}$ ) lies far below the plotted region. The tine increment, $\delta t$, is 3 seconds. This selection of 13 frames is abstracted from a 16-m motion picture of an actual 2UNI calculation, In which one such plot was drawn each cycle. The first frame of FIg. 22 shows the initial flat ocean surface. The second frame, at time $t=735 \mathrm{sec}$, shows the profile of a single solitary-11ke wave $140,000 \mathrm{~m}$ long and $1 \mathrm{~m}$ h1gh after $1 \mathrm{t}$ has been introduced through the left boundary. The succeeding frames dramatically show the decrease in wavelength and Increase in amplitude as the wave passes over shallower, 950-m-deep water. Finally, the wave is shown as it interacts with the rigid vertical right boundary of the computing mesh.

The 13 frames of $\mathrm{F}_{\mathrm{g}}, 23$ are abstracted from a calculation differing in that a continuing series 

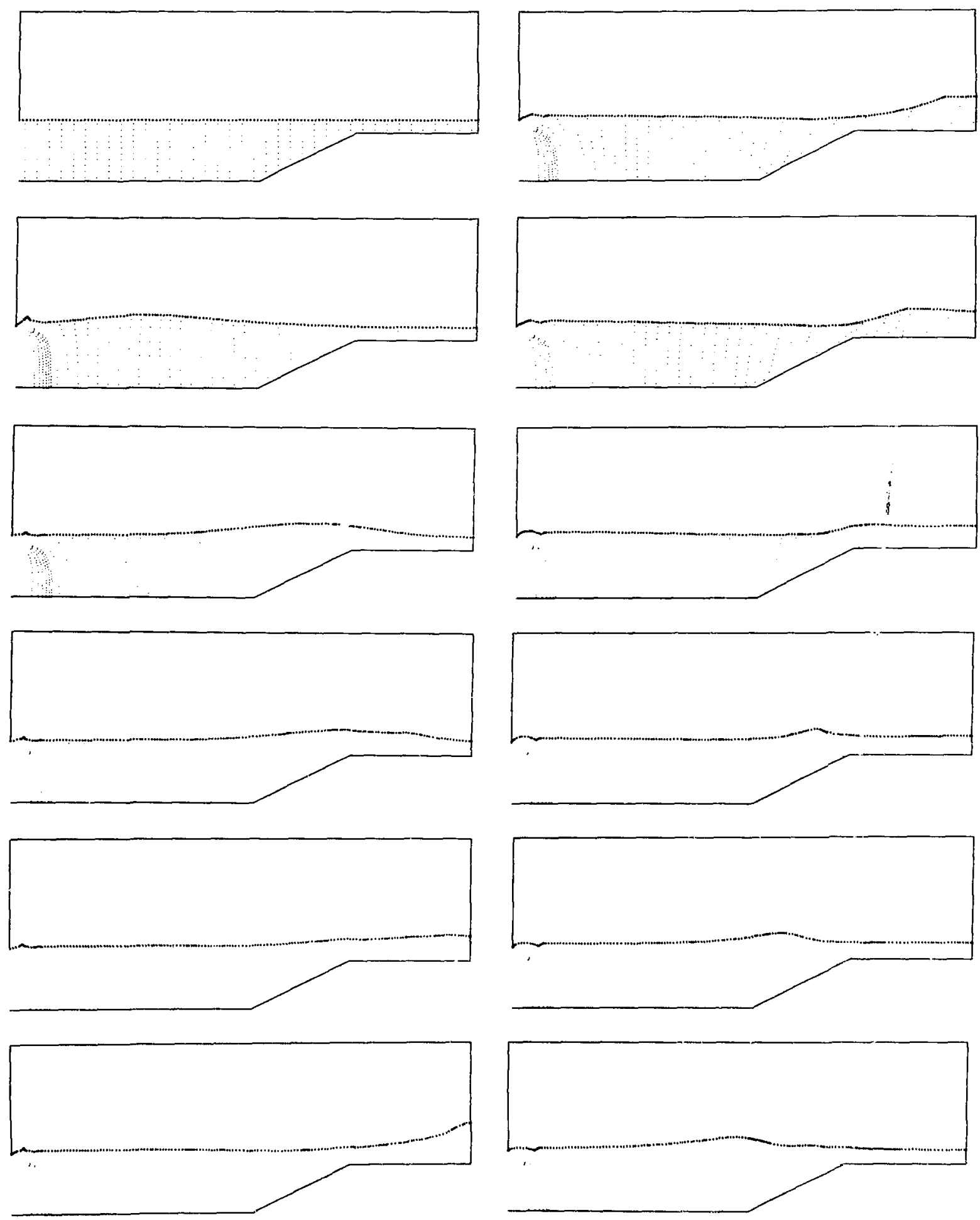

Fig. 17. A single solitary wave interacting with a submerged sloping beach. Surface markers are rapresented by heavy aster1sks, regulnr markers by light dots. Sequence of frames 10 down, then acrose. 


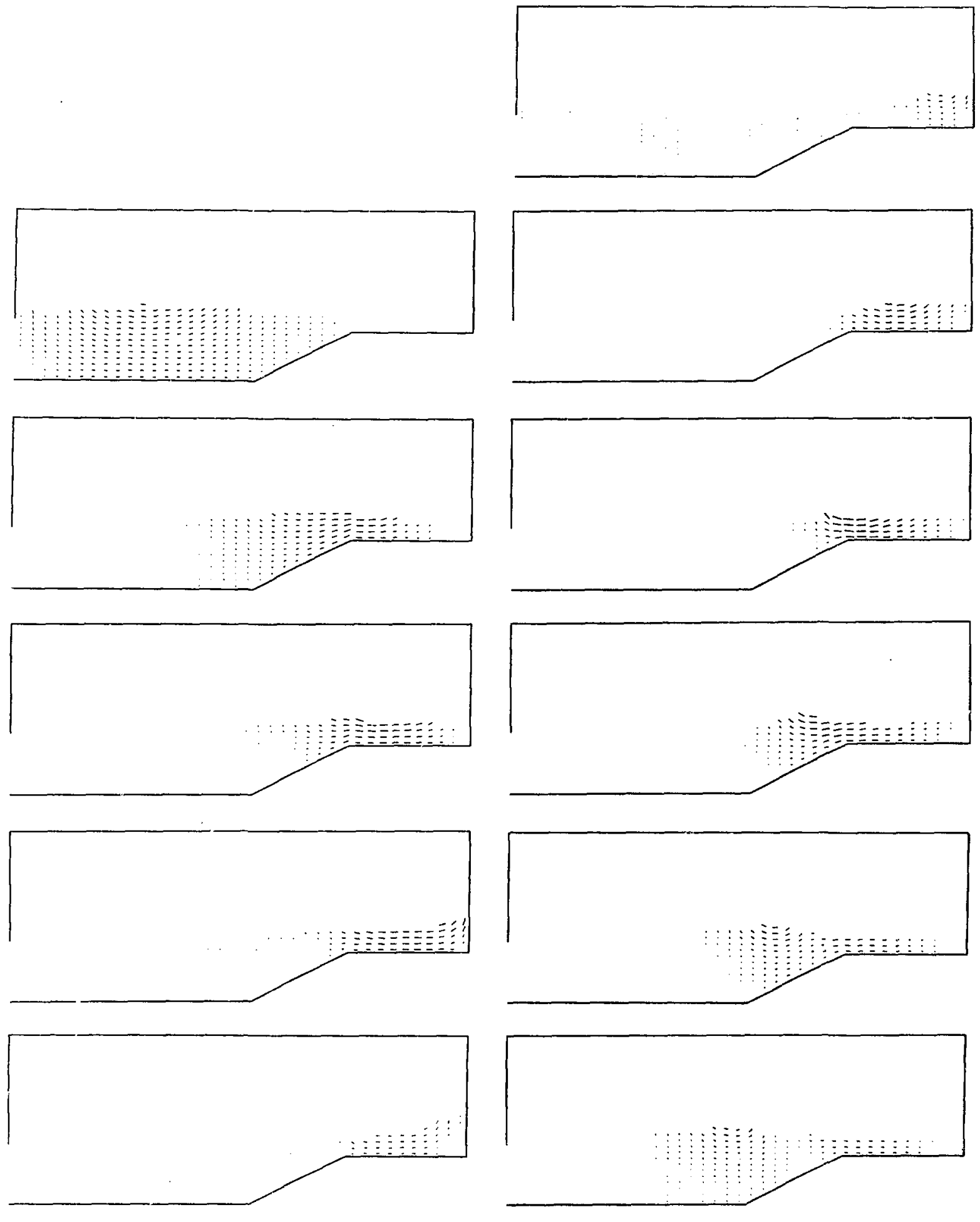

F13. 18. Velocity-vector plota for the problem shown in F18. 17. 


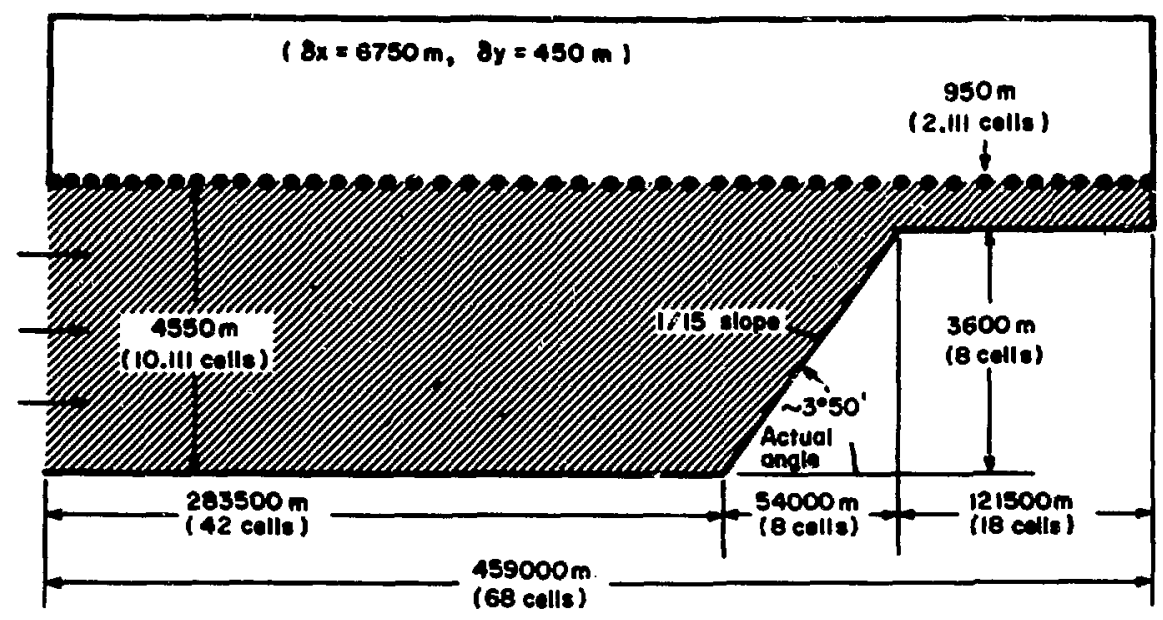

F18. 19. Schematic setup for calculating a teunami wave, drawn out of true proportion for visual clar1ty.

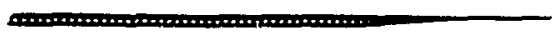

F18. 20. The particle plot for the problem of Fig. 19 drawn in true proportion.

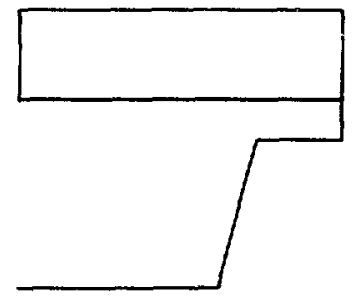

F18. 21. The particle plot of Fig. 20 reproportioned to exaggerate the vertical scale as much as posetble.

of solitazy-like waves are Introduced at the left boundary and the sloping wall 18 extended upward to penetrate the surface, Indicated by the termination of the surface-particle line. Note that the second wave risea to a higher amplitude than the firot upon reaching shallow water, in agreement with obeervations of shoaling waves. This to evident in a comparicon of the fifth frame ( $t-2172 \mathrm{Bec}$ ) with the seventh frame $(t-2727 \mathrm{sec})$. The frames in Figa. 22 and 23 correspond in time. Compartion with almiler calculations of the wave height above the undisturbed surface level shows excellent agreement with the best avallable shoaling-wave data, ${ }^{6}$ of ferIng a strong testimonial for the accuracy of the free-surface treatment.

The final set of examples 18 concerned wh flows up a sloping beach that 18 only partially exposed. In these examples, the Incoming waves have a truly oscillating form. The code modifications that allow exposed or submerged partial cells wero mods primarily to study the detalled interaction of a wave front with the beach ourface. Surface markers are the only particles uaed in these examples, allowing the neceasary negative inflow velocities. The plote in F1ge. 24-26 are drawn in true proportion, but they exclude the region covered by the leftmost two columns of interfor cells, because use of a simple, fixed, Inflow port whose size does not vary with the amplitude of the wave produces a misleading free-rurface appearance in the immediate vicinity of the left boundary.

F1gure 24 shows highs and lows of the wave front from a calculation in which the inflow veloc$1 t y, u_{L}$, 1a given by $u_{L}=0.2 \mathrm{sin}(\omega t)$. where the frequency w $=0.90$. Th1s frequency allows the osc1llating wave to run up the beach twice, but the wave breaks at the outset of the third run, at a time $t=20.8$, terminating the calculation. (Further code modifications thas described here would be required to allow calculation of a fully brealing; wave with the free-surface-marker particle treatment.) 


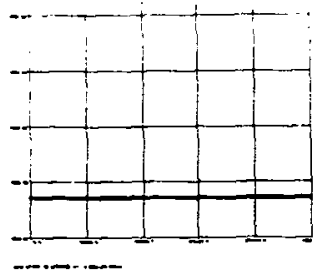

-..........

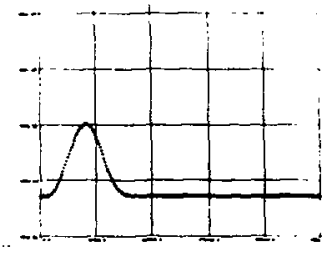

-........

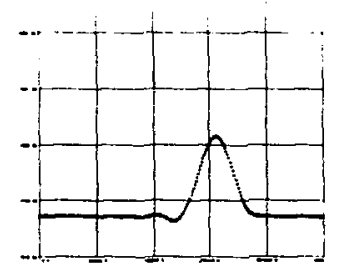

(.............
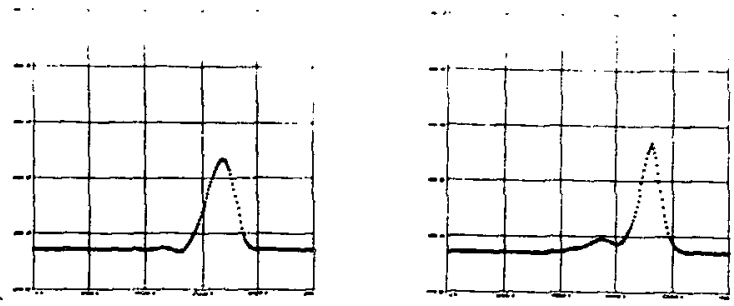

(..............

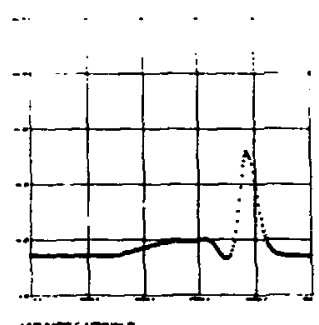

…….....

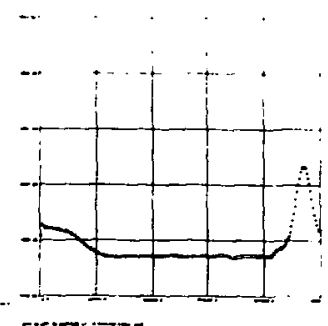

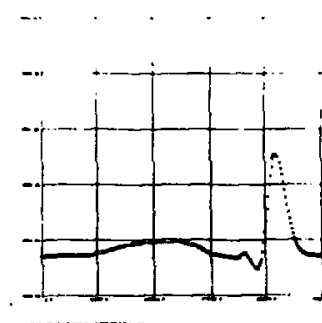

(..................

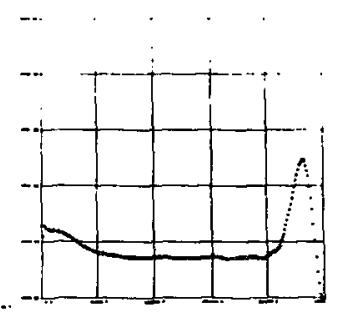

-............

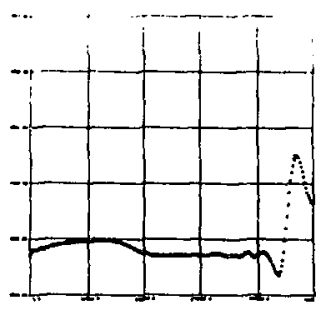

(................

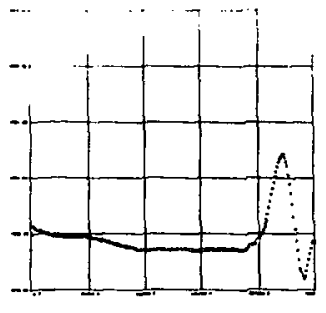

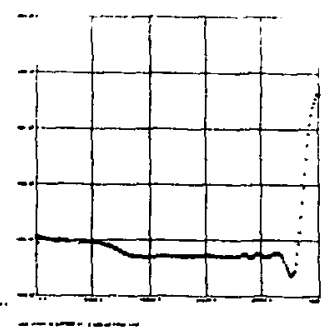

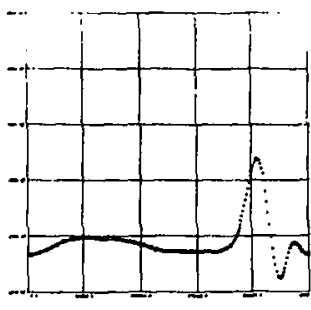

F1g. 22. Selected frames from a motion picture of the calculation shown in F1g. 19. These plots of surfacemarker particles cover a hor1zontal scale of $459,000 \mathrm{~m}$ and a vertical scale of 3.5 m (from 4549.5 to $4553.0 \mathrm{~m})$. Times are $0,735,1845,1971,2172,2403,2727,3225,3420,3750,3876,4071$, and 


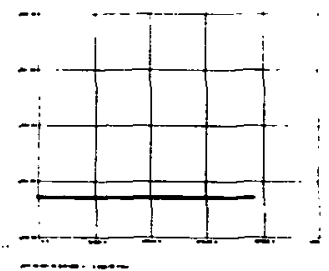

………

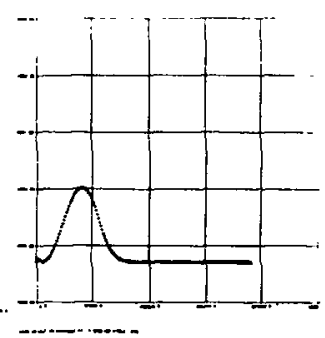

-...-.....

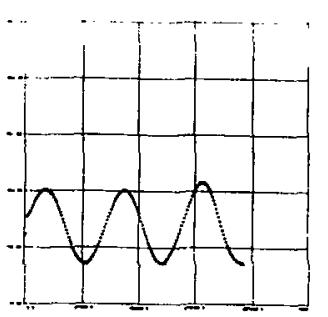

.............
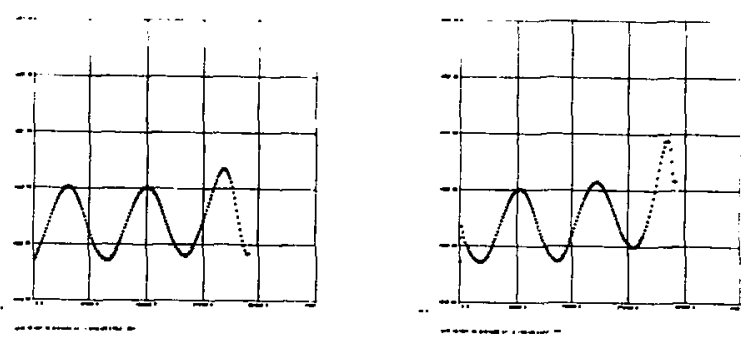

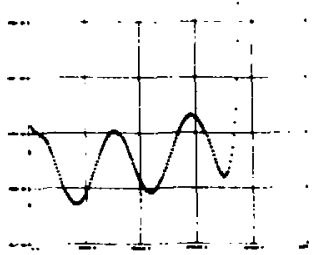

(n).....

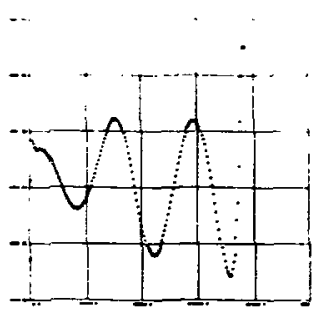

(n)

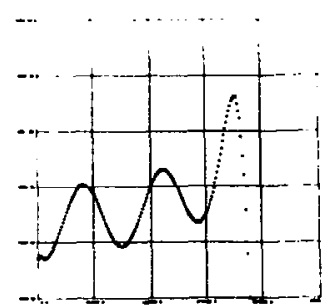

……....

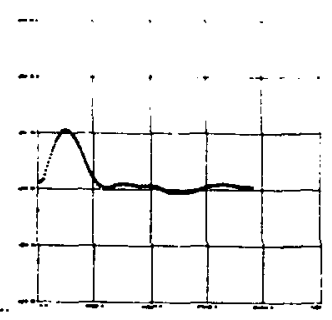

-..........

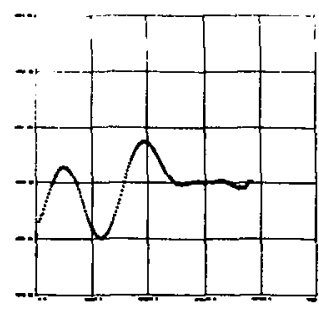

-........

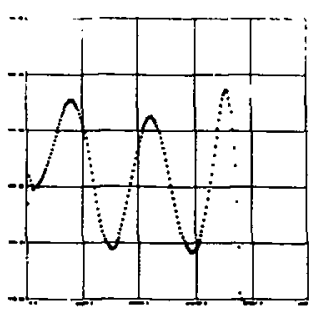

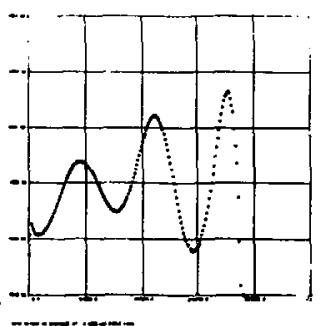

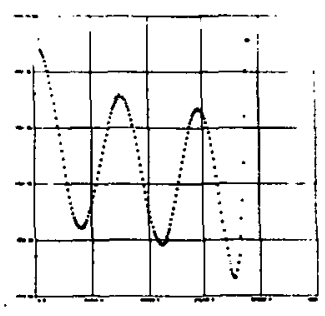

F1g. 23. A calculation similar to that of $\mathrm{Fig} .22$ except that the sloping obstacle 1s extended upward to penetrate the surface. Multiple waves are introduced at the left boundary. Times correspond to those of Fig. 22 . 

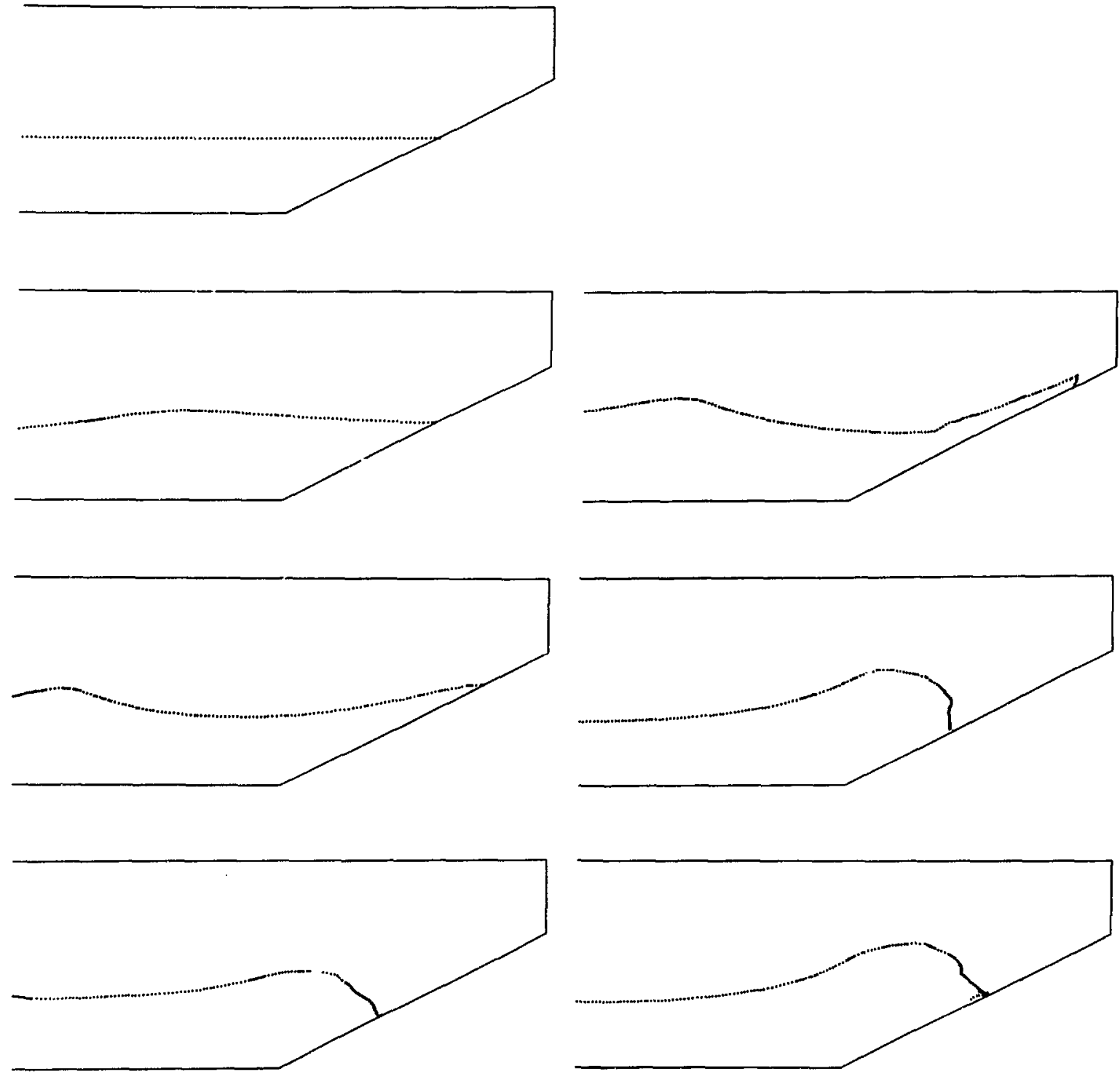

F1g. 24. An oscillating wave breaks on the third run up the beach. The Inflow velocity at the left boundary provides a wave frequency $\omega=0.90$. Sequence of frames 18 down, then across. 

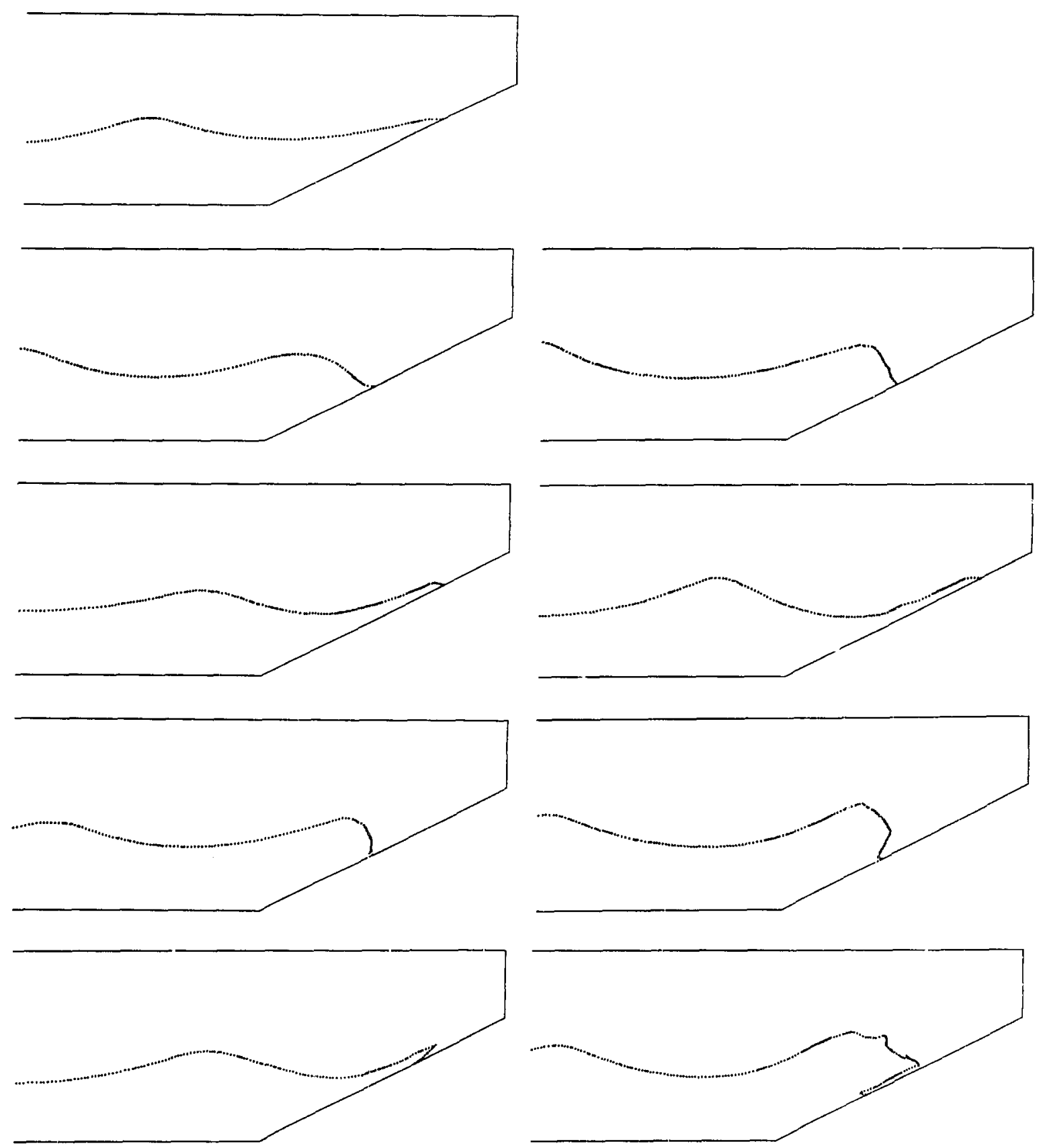

F1g. 25. Increasing the frequency to $\omega$. 1.14 delays the breaking untll the fifth run up the beach. Sequence of frames 18 down, then across. 

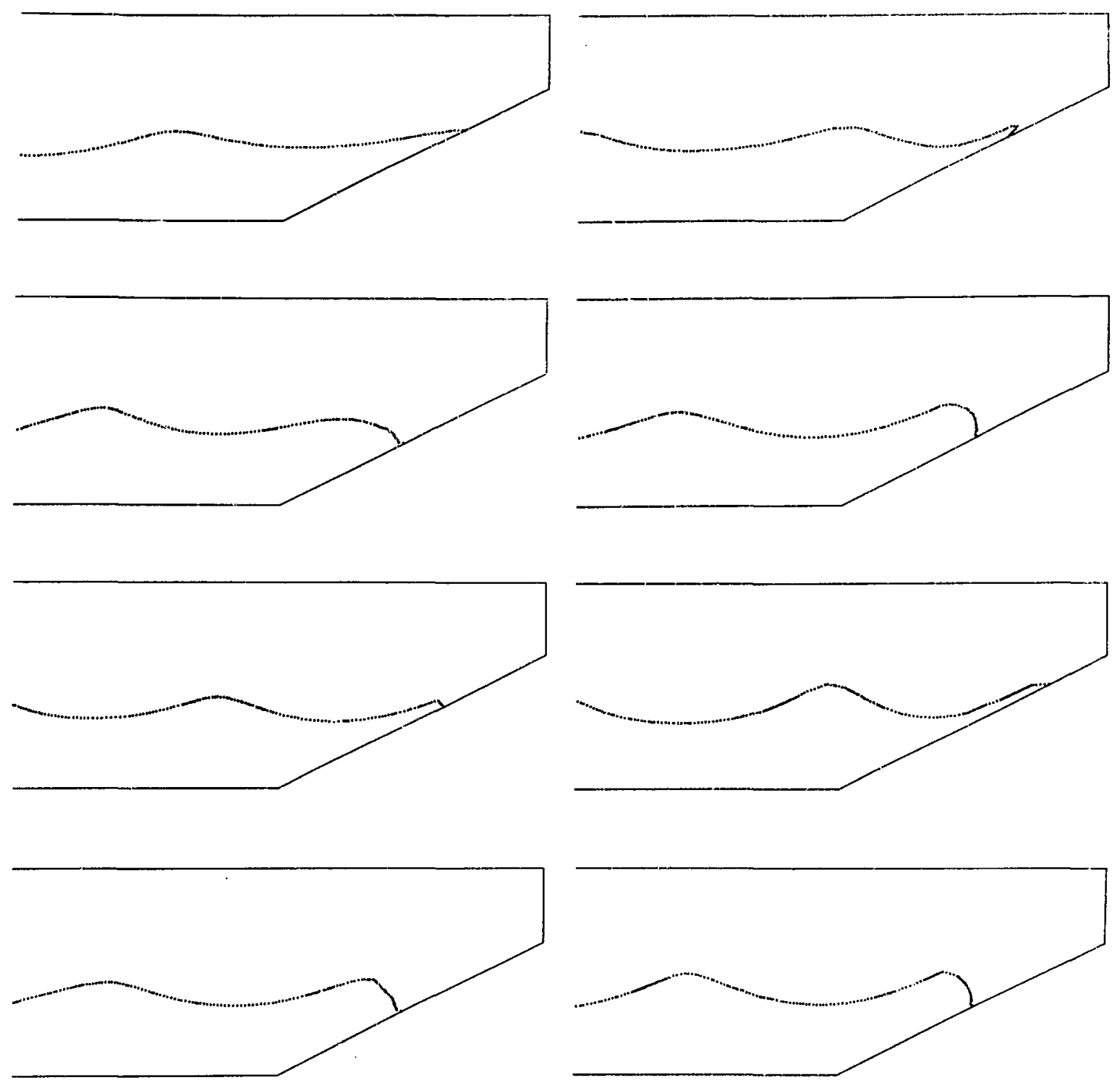

F1g. 26. Increasing the frequency st111 further $(\omega=1.30)$ prevented the wave from breaking at all in this calculation. Sequence of frames 18 down, then across. 
If the frequency of the fincoming wave is $1 \mathrm{n}-$ creased slightly, however, we observe that the wave's tendency to break is decreased or delayed. Th1s is 1llustrated by the calculation shown in F1g. 25, In which the frequency was increased to $\omega=1.14$, and the wave $\mathrm{d} 1 \mathrm{~d}$ not break completely and terminate the calculation unt1 the beginning of rhe $f 1 f$ th run up the beach, at a t1me $t=30.0$.

Increasing the wave frequency further to $\omega=1.30$, delayed wave breaking further, as shown in Fig. 26. The wave form at time $t=37.60 \mathrm{dif}-$ fers 11tele frow that at $t=23.04$. The osciliat1ng wave vas well behaved throughout the ent1re calculation, which was stopped after $t=41.0$ when the allotted computing time was exhausted.

\section{ACKNOWLEDGMENTS}

$I$ am Indebteú to $C$. L. Mader for the Inspiration to add these capabilities to the code for the Jotnt Tsunaml Research Effort, and for generously supplying a portion of the caiculational examples presented here; to $C$. W. H1rt, F. H. Harlow, and B. D. Nichols for technical advice; and, especially, to T, D. Butler for his assistance in the partialcell treatment.

\section{REFERENCES :}

1. J. E. Welch, F. H. Harlow, J. P. Shannon, and B. J. Daly, "The MAC Method," Los Alamos Sclent1f 1c Laboratory report LA-3425 (1965); F. H. Har. low and J. E. Welch, "Numerical Calculation of Time-Dependent Viscous Incompressible Flow," Phy's. Flu1ds $\underline{8}, 2182$ (1965).

2. C. W. HArt and J. P. Shannon, "Free-Surface Stress Conditions for Incompreasible-Flow Calculations," J. Comp. Phys. 2, 403 (1968).

3. A. A. Amsden and F. H. Harlow, "The SMAE Method: A Numerical Technique for Calculating Incompressible Fluid Flows," Los Alamos Sclentific Laboratory report LA-4370 (1970).

4. R. X.-C. Chan, R. L. Street, and T. Strelkoff, "Computer Studies of F士nite-Amplatude Water Waves," Stanford Unfversity Technical Report No. 104 (1969); R. K.-C. Chan and R. L. Street, J. Comp. Phys. 6, 68 (1970).

5. B. D. Nichols and C. W. Hrt, "Improved Free Surface Boundary Conditions for Numerical Incompressible-Flow Calculations," J. Comp. Phys. 8, 434 (1971).

6. C. L. Mader, "Numerical Simliation of Tsunamis," Hawa11 Institute of Geophysics Report, in press.

7. R. K. -C. Chan and R. L. Street, "SUMMAC - A Numerical Model for Water Waves," Stanford UnIversity Technical Report No, 135 (1970). 